\title{
Effects of particulate matter (PM) on childhood asthma exacerbation and control in Xiamen, China
}

\author{
Jinzhun Wu', Taoling Zhong ${ }^{2}$, Yu Zhu' ${ }^{1}$, Dandan Ge ${ }^{1}$, Xiaoliang Lin ${ }^{1}$ and Qiyuan Li $\mathrm{i}^{12^{*}}$
}

\begin{abstract}
Background: The short-term effects of particulate matter (PM) exposure on childhood asthma exacerbation and disease control rate is not thoroughly assessed in Chinese population yet. The previous toxic effects of PM exposure are either based on long-term survey or experimental data from cell lines or mouse models, which also needs to be validated by real-world evidences.

Methods: We evaluated the short-term effects of PM exposure on asthma exacerbation in a Chinese population of 3106 pediatric outpatientsand disease control rate (DCR) in a population of 3344 children using case-crossover design. All the subjects enrolled are non-hospitalized outpatients. All data for this study were collected from the electronic health record (EHR) in the period between January 1, 2016 and June 30, 2018 in Xiamen, China.

Results: We found that exposure to $\mathrm{PM}_{2.5}$ and $\mathrm{PM}_{10}$ within the past two weeks was significantly associated with elevated risk of exacerbation ( $\mathrm{OR}=1.049, p<0.001$ for $\mathrm{PM}_{2.5}$ and $\mathrm{OR}=1.027, p<0.001$ for $\mathrm{PM}_{10}$ ). In addition, exposure to $\mathrm{PM}_{10}$ was associated with decreased $\mathrm{DCR}\left(\mathrm{OR}=0.976\right.$ for $\left.\mathrm{PM}_{10}, p<0.001\right)$.

Conclusions: Our results suggest that exposure to both $\mathrm{PM}_{10}$ and $\mathrm{PM}_{2.5}$ has significant short-term effects on childhood asthma exacerbation and DCR, which serves as useful epidemiological parameters for clinical management of asthma risk in the sensitive population.
\end{abstract}

Keywords: Childhood asthma, Particulate matter, Exacerbation, Asthma control, Electronic health record;Xiamen

\section{Background}

Asthma is a chronic allergic respiratory disease with a heterogeneous background involving both genetic and environmental factors. In 2016, 339.4 million people worldwide were affected by asthma [1]. In China, the prevalence of asthma was $3.02 \%$ in children under 14 years old (95\%CI:2.97-3.06\%) [2]. Corticosteroids therapy can relieve the symptoms of asthma, however, the prevalence of asthma still increased significantly over the past 20 years [3, 4]. Exposure to all ergens in the pollutants is one of the major risk factors of asthma in children [5]. Evidence currently available has shown that many environmental factors, including allergens, airborne irritants, unfavorable weather conditions and

\footnotetext{
* Correspondence: qiyuan.li@xmu.edu.cn

${ }^{1}$ Department of Pediatrics, the First Affiliated Hospital of Xiamen University, No.55 Zhenhai Road, Xiamen 361003, China

${ }^{2}$ National Institute for Data Science in Health and Medicine, School of Medicine, Xiamen University, South Xiang'an Road, Xiamen 361102, China
}

adverse indoor environment, are associated with asthma progression [6, 7]. Inhalable particulate matter (PM) including $\mathrm{PM}_{2.5}$ and $\mathrm{PM}_{10}$ (inhalable particles with an aerodynamic diameter less than or equal to $2.5 \mu \mathrm{m}$ and $10 \mu \mathrm{m}$, respectively), is known as major environmental hazardous factors that impact human health [8-11]. Previous epidemiological studies have shown that high concentrations of $\mathrm{PM}_{2.5}$ and $\mathrm{PM}_{10}$ are associated with elevated mortality rate and increased incidence of many diseases, such as respiratory diseases, cardiovascular diseases, central nervous system diseases and inflammation [12-14]. In China, PM has become a major cause of air pollution due to rapid industrialization and urbanization in recent years $[15,16]$. This fact leads to growing concerns on the part of hospitals, government and the public about the health risks associated with PM. In particular, the ability of stakeholders to predict the impact of PM on public health is essential for hospitals to take 
timely and efficient actions to handle overwhelming outpatient volume caused by hazardous environmental conditions.

Most of the studies conducted worldwide addressed the relationship between PM exposure and asthma in terms of long-term effects and few assessed the impact of PM exposure on asthma control rate [17].Many studies address the transient effect of indoor and ambient pollutants and allergens on asthma exacerbation but less is known for particulate matters $[18,19]$. On the other hand, current empirical studies examining the toxic effects of PM exposure were mostly conducted in cell lines and mouse models based on case-control design. Real world evidence derived from electronic health record (EHR) is likely to provide more pragmatic and accurate estimate of the effects of PM exposure [20, 21].

It has been well documented that PM exposure causes specific immune responses in the airway [22-24]. PM induces inflammation, apoptosis, increased secretion of T-cell cytokines, and DNA damage [25, 26]. Asthmatic symptoms are documented in $14 \%$ of children worldwide [27]. Children are more susceptible to PM-related diseases because of higher breathing rates, narrower airways, immature lung tissue, and longer exposure time to outdoor ambient air $[28,29]$.

Xiamen is located on the southeast coast of China. The city is in typical subtropical climate zone. No study is available to address the short-term effects of PM on childhood asthma exacerbation and control rate in this area. Considering the increasing PM pollution in this area and growing public health concern over PM, there is a need to obtain further epidemiological evidences for public health service to take proper preventive measure to control the risk caused by PM exposure. Therefore,we designed this study to evaluate the effects of PM exposure on childhood asthma exacerbation and control rate.

\section{Methods}

\section{Patient data}

Childhood asthma data were collected from the electronic health record system of Pediatric Outpatient Department of the First Affiliated Hospital of Xiamen University (Joint Commission International accredited hospital). All subjects are outpatients between zero and 14-year-old, who were diagnosed with asthma exacerbation inthe period from January 1, 2016 to June 30, 2018.The diagnosis of childhood asthma is based on respiratory symptoms including wheezing, shortness of breath, chest tightness or cough (Additional file 1 Table 1 ). Patients with respiratory symptoms caused by other diseases were excluded. The classification of asthmafollowsthe International Classification of Disease 10 (ICD-10-CM) code of J45 [27]. The study was designed conforming to the ethical guidance (KY2015-027). For each case of acute exacerbation, the date of the latest asthma exacerbation was determined. Patients whose symptoms reappeared within 14 days were defined as the same one exacerbation, and the last exacerbation was selected as index exacerbation.

For asthma control, the outcome was determined upon return visit after four-week treatment since the initial visit based on Guidelines forthe Diagnosis and Treatment of Childhood Bronchial Asthma [30]. The outcome of the disease is defined for children aged below and above six separately (Additional file 1 Table 2). We further classify the cohort in to two subgroups, well-controlled asthma and uncontrolled or partly controlled asthma [31, 32]. Asthma was managed with budesonide aerosol inhalation, fluticasone MDI with spacerdevices, or budesonide or budesonide/formoterol powder in halation according to patients' age. The patients were followed up every oneto three months. In case of acute exacerbation, salbutamol aerosol or budesonide and aerosolized terbutaline solution for inhalation were added. Appropriate treatment was added if there was comorbidity, such as allergic rhinitis or infection. The outcome of asthma was assessed according to "Guidelines for the Diagnosis and Prevention of Asthma in Children" [30]. Disease control was rated as well controlled, partly controlled, or uncontrolled according to the daytime and night symptoms inthe past 4 weeks.

\section{Air pollution data}

Air pollution data were obtained from Xiamen Department of Environmental Protection. The concentration of pollutants was measured at different sites of the city. Daily average $\mathrm{PM}_{10}$ and $\mathrm{PM}_{2.5}$ concentrations were used to measure the exposure. Meteorological data including daily average ambient temperature,wind speed, cumulative precipitation, humidity and barometric pressure were obtained from Xiamen Meteorological Bureau.

\section{Statistical analysis}

Case-Crossover (CCO) designwas used to assess the effects of PM on asthma exacerbation. To measure the exposure to PM, we recorded the number of days of AQI (air quality index) level 2 or 3(24-h average of $\mathrm{PM}_{2.5}>35 \mu \mathrm{g} / \mathrm{m}^{3}$ and $\mathrm{PM}_{10}>50 \mu \mathrm{g} / \mathrm{m}^{3}$ ) [33] within two weeks preceding the onset of the index exacerbation(Fig. 1a). We also measured the four-week-exposure before the time point of control evaluation for rating disease control. The outcome of disease control was defined as 1 if asthma was controlled, or 0 if the disease was partly controlled or uncontrolled(Fig. 1b).

To evaluate the effects of PM exposure on asthma exacerbation and control rate, mixed effects logistic regression was performed,in which PM exposure was considered as a fixed effect and individual patient as 


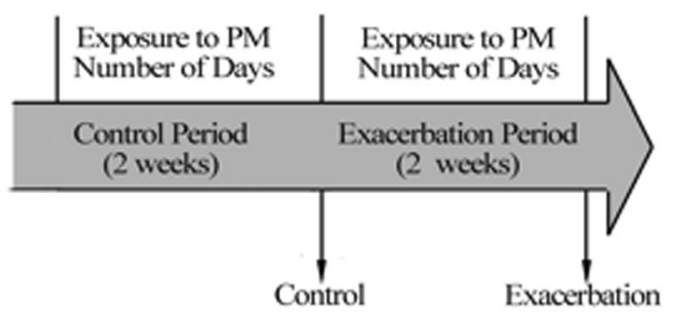

a

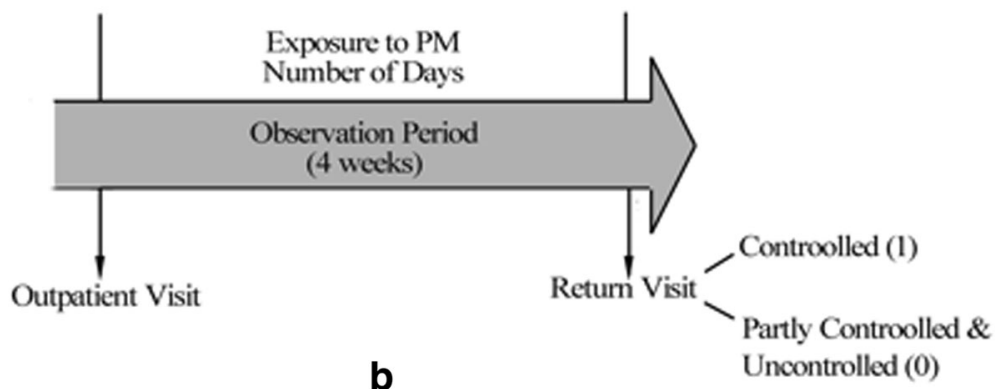

Fig. 1 Schematic view of the study design. Panel (a):For patients of acute exacerbation, the day two weeks before the exacerbation was considered as control. The PM exposures within 2 weeks before the exacerbation day and control day were recorded,respectively. Panel (b):The PM exposure within 4 weeks before the return visitwas recorded. Patients were assessed at follow-up visit based on the symptoms in the past 4 weeks

random effects. Fever and weather conditions including average temperature, cumulative precipitation and average wind speed were covariates in the model. We standardized the estimated odds ratio (OR) for each fixed effect to compare the effects of different factors.

The model is described as:

$$
\begin{gathered}
\operatorname{logit}(\mathrm{P})=\log \left(\frac{\mathrm{P}}{1-\mathrm{P}}\right)=\beta * \mathrm{M}+\tau * \mathrm{~T}+\gamma * \mathrm{R}+\omega * \mathrm{~W} \\
+\phi * \mathrm{~F}+\mu * \mathrm{~s}
\end{gathered}
$$

where, $\mathrm{P}$ is the probability of asthma exacerbation or control, $\mathrm{M}$ is the measure of exposure of $\mathrm{PM}_{2.5}$ or $\mathrm{PM}_{10}$; $\mathrm{S}$ is a random grouping variable corresponding to each individual; $\mathrm{T}$ is average temperature, $\mathrm{R}$ is cumulative precipitation, $\mathrm{W}$ is average wind speed and $\mathrm{F}$ is fever. $\beta, \tau$, $\gamma, \omega, \phi$ and $\mu$ are regression coefficients.

As there is high collinearity between $\mathrm{PM}_{10}$ and $\mathrm{PM}_{2.5}$, which is evidenced by pairwise Pearson correlation coefficient of 0.906 , which would lead to instability in effect estimates in multivariate regression analysis, the regression models were built with the two air pollutants separately.

All statistical procedures were conducted using R-3.5.

\section{Results}

\section{Summary of patient information}

A total of 3106 patients with 4728 cases of acute asthma exacerbation were identified from 16,355 cases of childhood asthma (Table 1). The patients included 2110
(67.9\%) males and 996 females (32.1\%). The age of these patients ranged from zero to fourteen years old. Patients aged four to six accounted for the largest proportion (39.9\%), showing that preschool children were affected by asthma mostly. In the control period, 53 patients (1.1\%) in the study had fever and during the 2 weeks before exacerbation there were 832 patients $(18.2 \%)$ who had fever. Among the 3443 returning-visit patients, 2292 (66.6\%) were males and 1151 (33.4\%) were females, and children aged four to six accounted for the largest proportion $(44.8 \%)$. In the course of the 4 weeks in which

Table 1 Patients' characteristics of the study cohorts

\begin{tabular}{llll}
\hline & & Number & Percentage \\
\hline Gender & Male & 2110 & 67.90 \\
Age(years) & Female & 996 & 32.10 \\
& $0-3$ & 1230 & 39.60 \\
& $4-6$ & 1238 & 39.90 \\
& $7-14$ & 638 & 20.50 \\
Return visit & Total & 3106 & 100 \\
Gender & & & \\
& Male & 2292 & 66.60 \\
Age(years) & Female & 1151 & 33.40 \\
& $0-3$ & 1127 & 32.70 \\
& $4-6$ & 1542 & 44.80 \\
& $7-14$ & 774 & 22.50 \\
& Total & 3443 & 100 \\
\hline
\end{tabular}


we assessed the control level of the patients, $6.6 \%$ of the patients had fever. There are nine subtypes of $J 45$ present in the cohort (Additional file 2 Figure 1a). Bronchial asthma (J45.903) makes the majority of the cohort (41.2\%), followed by asthmatic bronchitis (J45.901, 26.2\%) and cough variant asthma (J45.005, 19.7\%). The other subtypes (J45.004, J45.900, J45.000, J45.904, J45.006 and J45.003) cover $12.9 \%$ of the cohort.

\section{Summary of the exposure measures and covariates}

The summary statistics of environmental variables were summarized in Table 2. During the study period, the daily levels of $\mathrm{PM}_{2.5}$ ranged from 6 to $110 \mu \mathrm{g} / \mathrm{m}^{3}$ with an annual mean of $27.44 \mu \mathrm{g} / \mathrm{m}^{3}$. The mean $\mathrm{PM}_{2.5}$ concentration was $2.16 \%$ lower than the Grade II Annual $\mathrm{PM}_{2.5}$ Standard of CNAAQS $\left(35 \mu \mathrm{g} / \mathrm{m}^{3}\right)$, but 2.7 times higher than the annual average $\operatorname{PM}_{2.5}\left(10 \mu \mathrm{g} / \mathrm{m}^{3}\right)$ in WHO guideline. Daily levels of $\mathrm{PM}_{10}$ ranged from 11 to $141 \mu \mathrm{g} /$ $\mathrm{m}^{3}$ with an annual mean of $47.66 \mu \mathrm{g} / \mathrm{m}^{3}$. The exposure of $\mathrm{PM}_{2.5}$ for the cohort ranged from 0 to 7 days in one week before the exacerbation, and 0 to 14 days in two weeks before the exacerbation(Fig. 2). The exposure of $\mathrm{PM}_{10}$ for the cohort ranged from 0 to 7 days in one week and 0 to 14 days in two weeks (Fig. 3). The average exposure to PM was 2 days in one week and 4 days in two weeks for $\mathrm{PM}_{2.5}$, and 3 days in one week and 6 days in two weeks for $\mathrm{PM}_{10}$.

As for the weather conditions during the study period, the average daily temperature ranged from $3.9-31{ }^{\circ} \mathrm{C}$ (annual average $21.3^{\circ} \mathrm{C}$ ) during the study period. The average precipitation ranged from 0 to $172.7 \mathrm{~mm}$ (annual average $4.07 \mathrm{~mm}$ ). And the average wind speed ranged from 2 to $9.6 \mathrm{~m} / \mathrm{s}$ (annual average $2.68 \mathrm{~m} / \mathrm{s}$ ).

\section{PM exposure versusRisk of exacerbation}

The exposureto $\mathrm{PM}_{2.5}$ in one week (Standardized $\mathrm{OR}=$ 1.091; 95\% CI: [1.029, 1.157]; $p=0.003)$ and two weeks (Standardized OR $=1.161 ; 95 \% \mathrm{CI}:[1.084,1.243] ; p<$ 0.001 ) were both significantly associated with higher risk of asthma exacerbation (Fig. 4, Table 3a). And the effect of $\mathrm{PM}_{2.5}$ exposure in two weeks was more severe than the exposure in one week.

Just like $\mathrm{PM}_{2.5}, \mathrm{PM}_{10}$ exposure during one week and two weeks showed a significant increase in the risk of asthma attacks. Each incremental day of exposure increased the risk of asthma onset by $7.12 \%(p=0.015$; $95 \%$ CI: $[1.3,13.2 \%]$, in one week $)$ and $10.64 \%(p<0.001$; 95\% CI: [4.2, 17.5\%], in two weeks) (Table 3b).

As for weather conditions, temperature and wind speed had significant effect on asthma exacerbation. Rise of temperature increased the risk of asthma exacerbation, and increase in wind speed reduced the risk of asthma exacerbation. When exposed to $\mathrm{PM}_{2.5}$, the standardized OR of the temperature during one week was $1.049(p=0.079)$. The standardized OR of the temperature during two weeks was $1.125(p<0.001)$ (Table 3a). When exposed to $\mathrm{PM}_{10}$, the standardized OR of the temperature during two weeks was $1.079(p=$ 0.008) (Table 3b). In addition, when exposed to $\mathrm{PM}_{10}$, the standardized OR of wind speed in one week was $0.950(p=0.021)$, and the standardized OR of wind speed in two weeks was $0.954(p=0.033)$ (Table 3b).

Fever had a significant effect on asthma exacerbation. When exposed to $\mathrm{PM}_{2.5}$ for two weeks, the standardized OR of fever was $2.402(p<0.001)$, and as for $\mathrm{PM}_{10}$, the standardized OR was $2.401(p<0.001)$.

\section{Association between PM exposure and disease control rate of childhood asthma}

During the whole period, the exposure of $\mathrm{PM}_{2.5}$ and $\mathrm{PM}_{10}$ was higher in winter and lower in summer, while the control rate peaked in summer and was the lowest in winter (Fig. 5a). With the increase of days of PM exposure, the control rate showed a downward trend (Fig. 5b).

Among the 3443 returning patients, $\mathrm{PM}_{2.5}$ exposure did not affect the control rate $(p=0.347$, Fig. 6a, Table 4),however exposure to $\mathrm{PM}_{10}$ had a negative effect on childhood asthma control rate (Fig. 6b, Table 4),as each increasing day of exposure to $\mathrm{PM}_{10}$ reduced the odds of childhood asthma control by $15.18 \%$ (standardized OR $0.848 ; 95 \%$ CI: [0.786,0.915], $p<0.001$ ). Fever was associated with the decrease of DCR (standardized OR of $\mathrm{PM}_{2.5}$ was 0.923 and standardized OR of $\mathrm{PM}_{10}$ was 0.924$)$.

\section{Discussion}

Our study confirmed that the exposure to $\mathrm{PM}_{2.5}$ and $\mathrm{PM}_{10}$ within one or two week sposed significant risk to exacerbation of childhood asthma in Xiamen, China.

Table 2 Overview of environmental variables in Xiamen

\begin{tabular}{|c|c|c|c|c|c|c|c|}
\hline & Mean & SD & Minimum & First quartile & Median & Third quartile & Maximum \\
\hline $\mathrm{PM}_{2.5}\left(\mu \mathrm{g} / \mathrm{m}^{3}\right)$ & 27.44 & 14.535 & 6 & 17 & 24 & 35 & 110 \\
\hline $\mathrm{PM}_{10}\left(\mu \mathrm{g} / \mathrm{m}^{3}\right)$ & 47.66 & 22.779 & 11 & 31 & 43 & 60 & 141 \\
\hline Temperature $\left({ }^{\circ} \mathrm{C}\right)$ & 21.30 & 6.22 & 3.9 & 15.97 & 22.05 & 27.12 & 31 \\
\hline Precipitation $(\mathrm{mm})$ & 4.07 & 12.76 & 0 & 0 & 0 & 0.9 & 172.7 \\
\hline Wind speed $(\mathrm{m} / \mathrm{s})$ & 2.68 & 1 & 2 & 2 & 2.5 & 3.2 & 9.6 \\
\hline
\end{tabular}




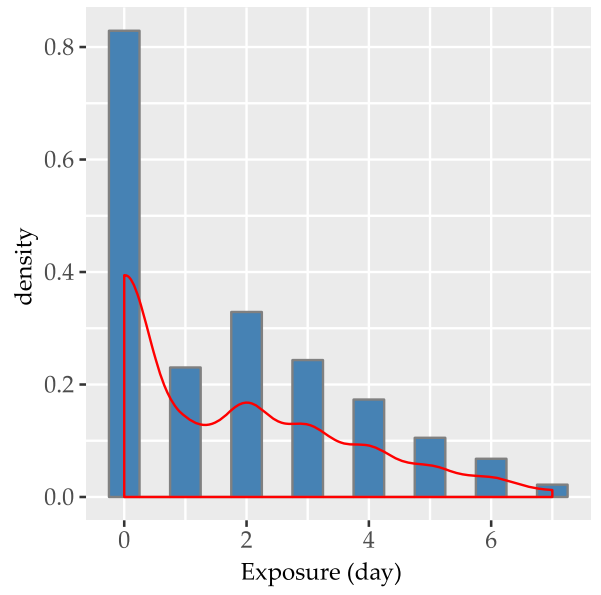

a

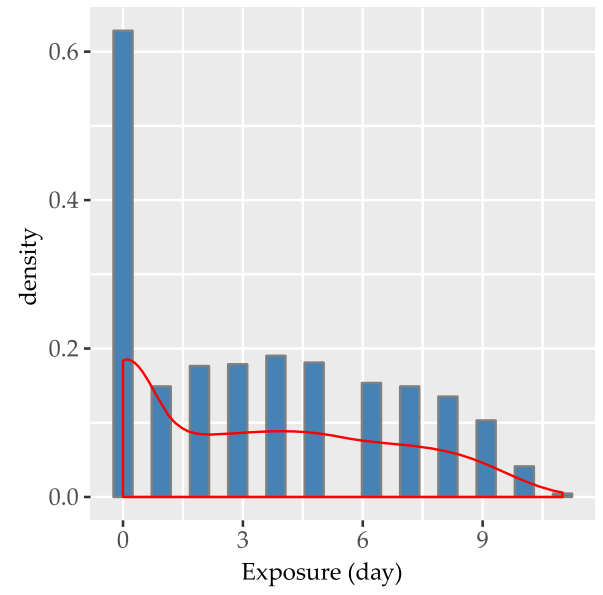

b

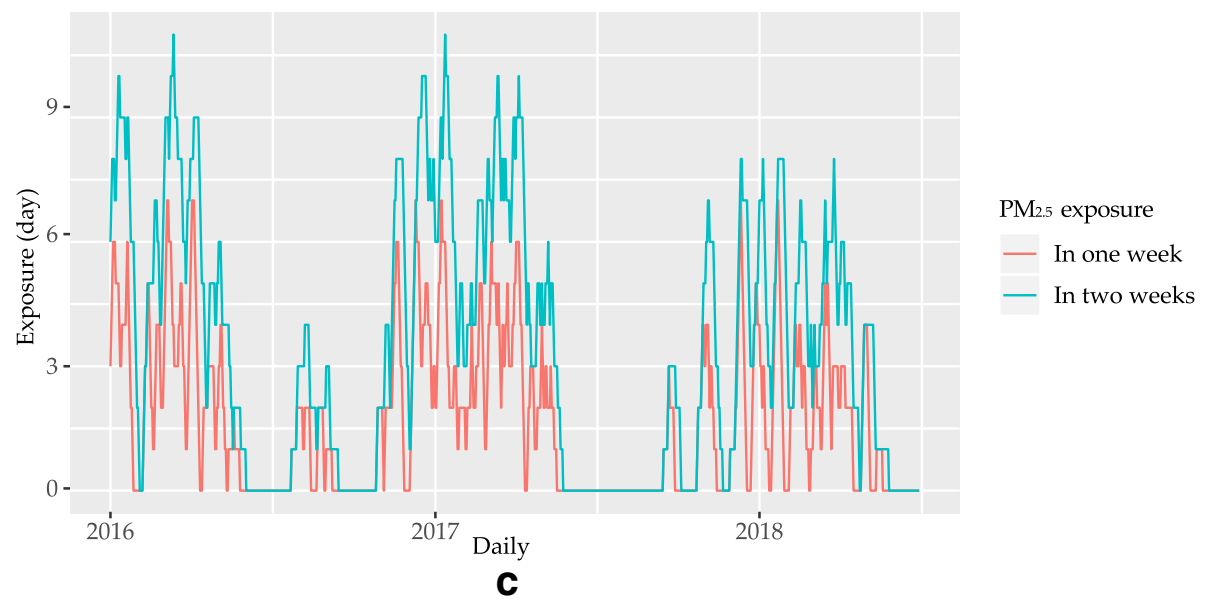

Fig. 2 Distribution and exposure leveltoPM 2.5 . Panel(a): Distribution of exposure days of $\mathrm{PM}_{2.5}$ in one week before the exacerbation and the density curve;Panel(b): Distribution of exposure days of $\mathrm{PM}_{2.5}$ in two weeks before the exacerbation and the density curve; Panel(c): Exposure days of $\mathrm{PM}_{2.5}$ in one week (red line) and in two weeks (blue line) before the exacerbation

The risk of PM exposure was independent on the effects of other pollutants, weather conditions, or individual variation. In addition, our data suggested that the effect of exposure to PM lasted for at least weeks.

The association between PM exposure and the risk of asthma has been studied in different regions of the world and consensus have been reached that high exposure to PM causes increased risk of exacerbation and admission rate [34]. For example, one study conducted in Seattle, Washington suggested that for every $11 \mu \mathrm{g} / \mathrm{m} 3$ increase in $\mathrm{PM}_{2.5}$ concentration, the $\mathrm{OR}$ of childhoodasthma was 1.15 (95\% CI: 1.08 to 1.23) [35]. An Australian survey which sampled 36,024 hospitalized patients with asthma showed that the impacts of $\mathrm{PM}_{2.5}, \mathrm{NO}_{2}$, $\mathrm{PM}_{10}$ and pollen in the cold season on hospitalization for asthma were $30.2 \%$ (95\% CI: 13.4 to $49.6 \%$ ), $12.5 \%$ (95\% CI: 6.6 to $18.7 \%$ ), $8.3 \%$ (95\% CI: 2.5 to $14.4 \%$ ), and $4.2 \%$ (95\% CI: 2.2 6.1\%), respectively [36]. Taiwanese scholars used the open data of the government to investigate the air pollution in different urban models using time-stratified case crossover studies and conditional logistic regression analysis in 4237 hospitalized children with asthma in Taipei and Kaohsiung from 2001 to 2010 [37]. The results showed that the risk of hospitalization for childhood asthma was significantly correlated with air pollutants. After being adjusted by season, the air pollution in Kaohsiung City had greater impact on the hospitalization of childhood asthma than that in Taipei.

Although many studies addressed the effects of PM exposure on asthma risk in the long-term [17], less is known about the transient effects of PM exposure in the scale of weeks. Several recent studies address the effects of PM exposure on asthma exacerbation in short-term in Ningbo, Taipei, Seoul and Detroit [38-41]. According to these reports, the highest effect size of PM exposure on asthma exacerbation ranges from 5 to 10 days. In order to accommodate the lagged effect we estimated the effect size for one week and two weeks of exposure, respectively. Our 

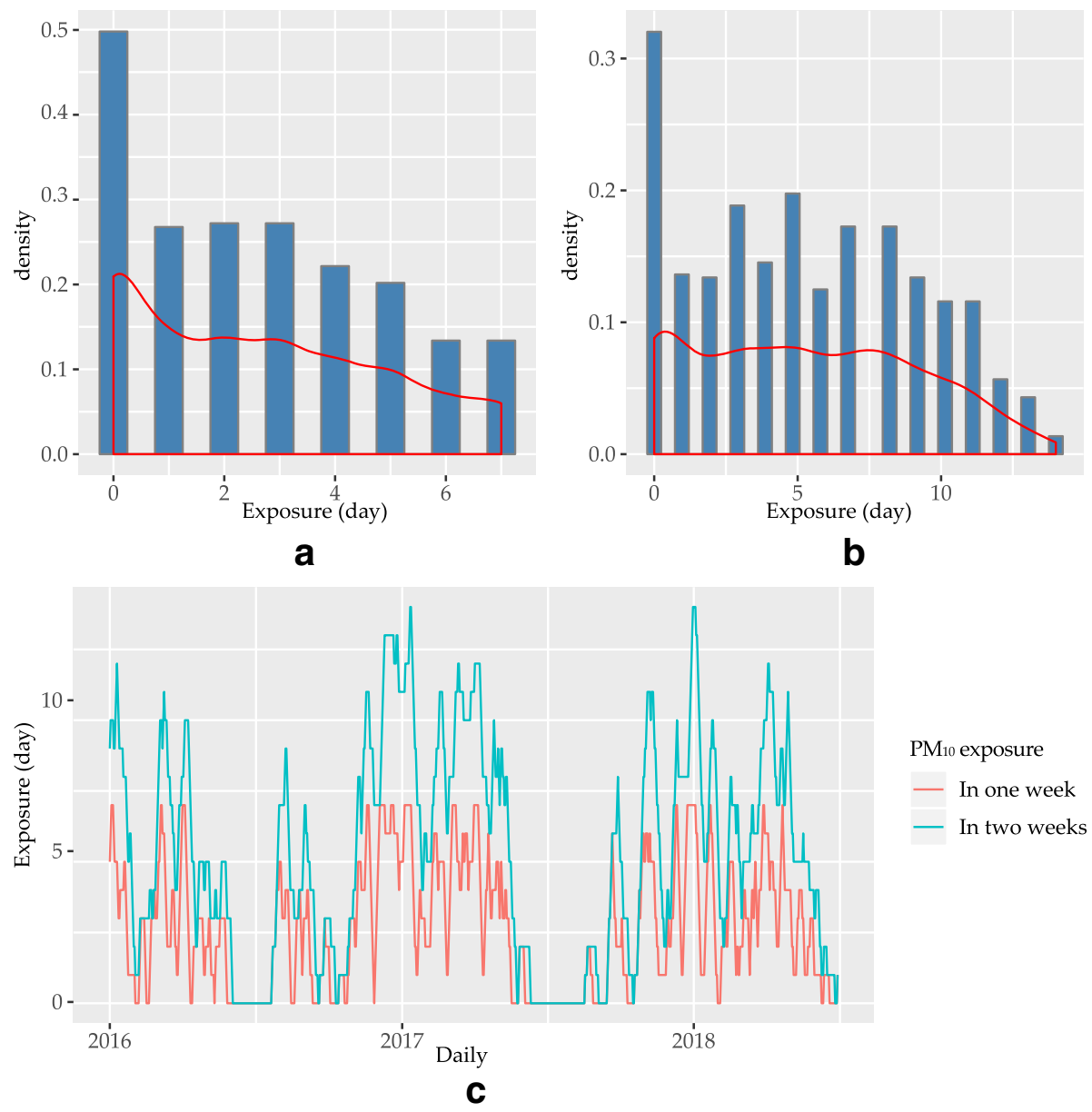

Fig. 3 Distribution and exposure level to $\mathrm{PM}_{10}$.Panel (a): Distribution of exposure days of $\mathrm{PM}_{10}$ in one week before the exacerbation and the density curve; Panel(b): Distribution of exposure days of $\mathrm{PM}_{10}$ in two weeks before the exacerbation and the density curve; Panel(c): Exposure days of $\mathrm{PM}_{10}$ in one week (red line) and in two weeks (blue line) before the exacerbation

data confirm PM exposure as a risk factor to asthma exacerbation and the effect peaks at two weeks of exposure, which is consistent to prior studies. Moreover, our results suggest PM exposure has a negative effect on the disease control rate, which provided extra evidence for the hazardous impact of PM on childhood asthma. In an investigation of commuters, PM2.5 exposure was associated with lower FEV1\% predicted among participants with below-median asthma control ( $3 \mathrm{~h}$ postcommute: $-7.2[95 \% \mathrm{CI}=-11.8$, 2.7]) [42]. A study in El Paso, Texas showed positive associations between Asthma Control Questionnaire (ACQ) scores and 96-h effects of $\mathrm{PM}_{10}, \mathrm{PM}_{2.5}$, black carbon, $\mathrm{NO} 2$ and ozone. In this study, the ACQ was used to evaluate asthma control [43]. Scottish scholars found that there is an exposure-response relationship between indoor $\mathrm{PM}_{2.5}$ concentration and poorer asthma control in children prescribed inhaled corticosteroids (ICS) [44]. The effect of $\mathrm{PM}_{2.5}$ in this study is reported after 5 days of exposure.

Prior studies use different measures to quantify the level of exposure to PM $[39,40]$. In this study, we used the "Technical Regulation on Ambient Air Quality Index" (AQI, HJ 633-2012) [33] issued by Chinese government as an official standard classify air quality and use the total number of days of level 2 and 3 as a measure of exposure. The regional AQI is based on air-pollution measures from different sites and normalized for geological variations hence more accurate and comprehensive. In addition, the use of AQI makes our data directly applied to the regulation policies of pollution control and public health. There are other ways to measure the exposure to $\mathrm{PM}$, such as the average concentration. Our results based on exposure days are consistent with and complementary to the prior studies.

PM exposure is not a stand-alone risk of asthma exacerbation. It has been previously shown that weather conditions, other environmental exposure, infections and self-management all contribute to the exacerbation of asthma. Our study is based on case-crossover design where each subject serves as its own control. Such a design can effectively remove inter-subject variations such 


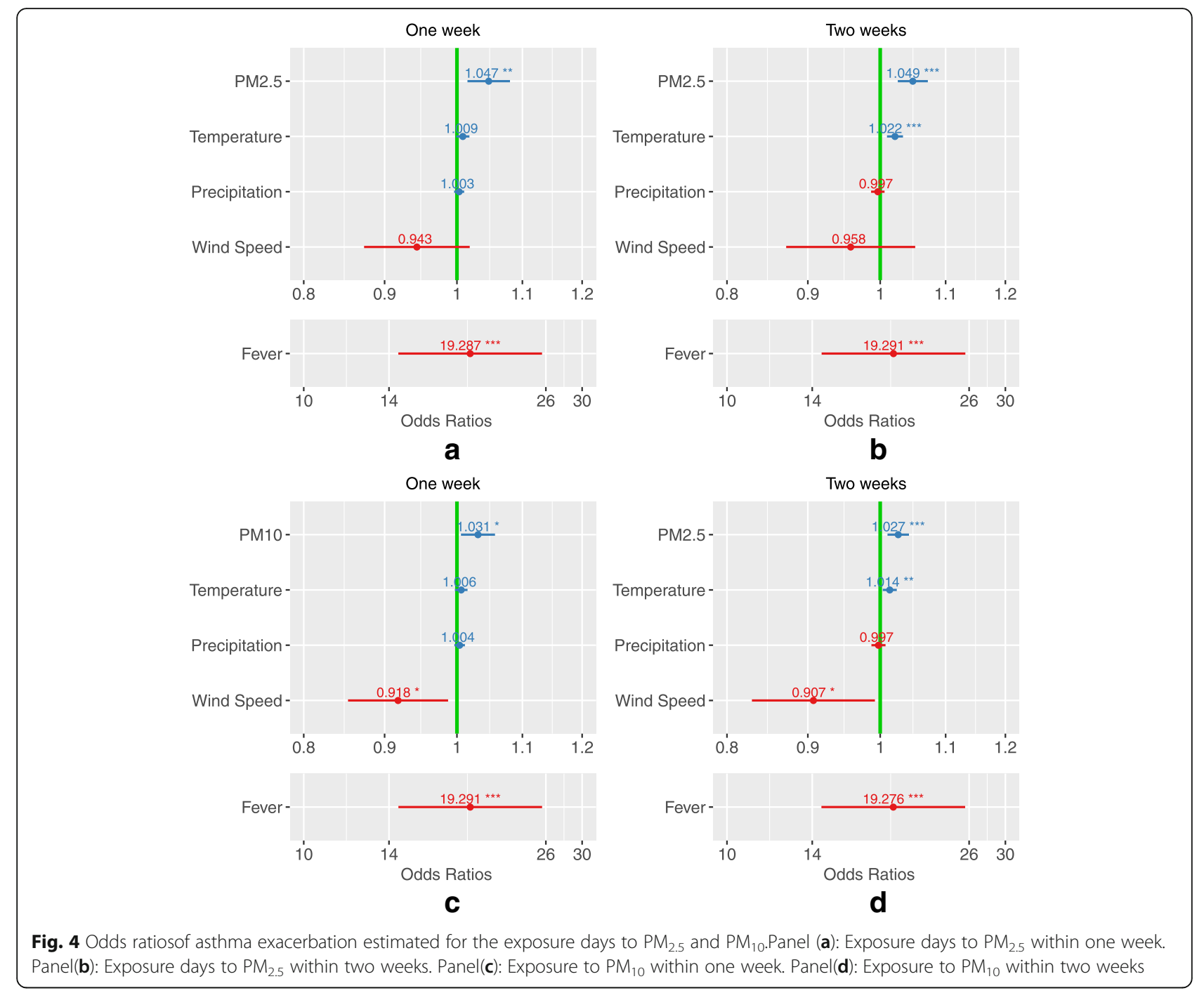

as self-management. As for the weather conditions, temperature, barometric pressure and humidity are tightly correlated with each other, therefore, we kept only temperature to avoid collinearity. Co-morbid infections are not directly measured in the data we obtained but at the same time strongly affect the exacerbation of asthma. Therefore, we used surrogate variables such as the record of fever in the history of present illness.

To estimate the effect of PM exposure on DCR, we combine the uncontrolled and partly controlled subject into one group. The same classification is used in prior clinical studies of asthma exacerbation [31, 32]. Plus, around $20 \%$ of partly controlled asthma will develop into uncontrolled disease and has a risk of exacerbation $(0.1 \%)[45,46]$.

In spite of the growing concern over air pollution caused by PM, the hospitals and public health services in China still lack accurate regional assessment of the risk posed by PM exposure, which is required for risk management and preventative measures. The resultsofour study provided basis for preventative and clinical management of the exacerbation risk of asthma. In particular, we also described a method based on case-crossover design that can apply to other regions of the country.

Real-world evidence (RWE) has become increasingly important in medical and epidemiological research. Our study based on information extracted from local EHR database provides a plausible pipeline to address environmental risk factors using RWE, which enables more accurate estimate of the effects in large population. On the other hand, unknown bias factors can confound the analysis based on RWE, therefore we have considered all possible covariates. More importantly, the casecrossover design is based on self-control, thus, less affected by sampling biases.

Finally, the biological mechanism of the toxicity of PM is not fully elucidated inhuman. However, many studies 
Table 3 a. Odds ratios of asthma exacerbation for exposure days to $\mathrm{PM}_{2.5}$. b. Odds ratios of asthma exacerbation for exposure days toPM 10

\begin{tabular}{|c|c|c|c|c|c|}
\hline Variable & OR & Standardized OR & \%increase & Standardized 95\%Cl & $P$-value \\
\hline \multicolumn{6}{|l|}{ One-week-model } \\
\hline $\mathrm{PM}_{2.5}$ Exposure (day) & 1.047 & 1.091 & 9.10 & {$[1.029,1.157]$} & $0.003^{* *}$ \\
\hline Temperature $\left({ }^{\circ} \mathrm{C}\right)$ & 1.009 & 1.049 & 4.89 & {$[0.994,1.106]$} & 0.079 \\
\hline Precipitation(mm) & 1.003 & 1.020 & 1.96 & {$[0.975,1.066]$} & 0.397 \\
\hline Wind Speed $(\mathrm{m} / \mathrm{s})$ & 0.943 & 0.966 & -3.44 & {$[0.922,1.011]$} & 0.137 \\
\hline Fever & 19.287 & 2.401 & 140.15 & {$[2.208,2.612]$} & $<0.001^{* * *}$ \\
\hline \multicolumn{6}{|l|}{ Two-week-model } \\
\hline $\mathrm{PM}_{2.5}$ Exposure(day) & 1.049 & 1.161 & 16.06 & {$[1.084,1.243]$} & $<0.001^{* * *}$ \\
\hline Temperature $\left({ }^{\circ} \mathrm{C}\right)$ & 1.022 & 1.125 & 12.52 & {$[1.056,1.199]$} & $<0.001^{* * *}$ \\
\hline Precipitation(mm) & 0.997 & 0.984 & -1.57 & {$[0.941,1.030]$} & 0.492 \\
\hline Wind Speed(m/s) & 0.958 & 0.979 & -2.08 & {$[0.935,1.025]$} & 0.370 \\
\hline Fever & 19.291 & 2.402 & 140.16 & {$[2.208,2.612]$} & $<0.001^{* * *}$ \\
\hline \multicolumn{6}{|l|}{ One-week-model } \\
\hline $\mathrm{PM}_{10}$ Exposure(day) & 1.031 & 1.071 & 7.12 & {$[1.013,1.132]$} & $0.015^{*}$ \\
\hline Temperature $\left({ }^{\circ} \mathrm{C}\right)$ & 1.006 & 1.035 & 3.53 & {$[0.984,1.090]$} & 0.184 \\
\hline Precipitation(mm) & 1.004 & 1.024 & 2.40 & {$[0.977,1.073]$} & 0.323 \\
\hline Wind Speed(m/s) & 0.918 & 0.950 & -5.01 & {$[0.909,0.992]$} & $0.021^{*}$ \\
\hline Fever & 19.291 & 2.402 & 140.16 & {$[2.208,2.612]$} & $<0.001^{* * *}$ \\
\hline \multicolumn{6}{|l|}{ Two-week-model } \\
\hline $\mathrm{PM}_{10}$ Exposure(day) & 1.027 & 1.106 & 10.64 & {$[1.042,1.175]$} & $<0.001^{* * *}$ \\
\hline Temperature $\left({ }^{\circ} \mathrm{C}\right)$ & 1.014 & 1.079 & 7.93 & {$[1.020,1.142]$} & $0.008^{* *}$ \\
\hline Precipitation(mm) & 0.997 & 0.989 & -1.15 & {$[0.943,1.036]$} & 0.633 \\
\hline Wind Speed(m/s) & 0.907 & 0.954 & -4.65 & {$[0.913,0.996]$} & $0.033^{*}$ \\
\hline Fever & 19.276 & 2.401 & 140.11 & {$[2.208,2.611]$} & $<0.001^{* * *}$ \\
\hline
\end{tabular}

confirm that the toxicity of PM is related to the immunogenicity and the consequential immune responses using cell line and animal model [47]. In OVA-sensitized mice, exposure to PM promote the proliferation of peribronchial lymph nodes and the activation of T-help cell subtype 2 which provokes inflammation in airway [48,
49]. Other studies suggest exposure to PM result in an increment of both neutrophils and eosinophils [50]; it also causes imbalance activities of Th1/Th2 through the activation of TNF- $\alpha$ and suppression of INF- $\gamma[51,52]$. Moreover, prior studies also demonstrate that exposure to PM affect with the activities of monocytes and
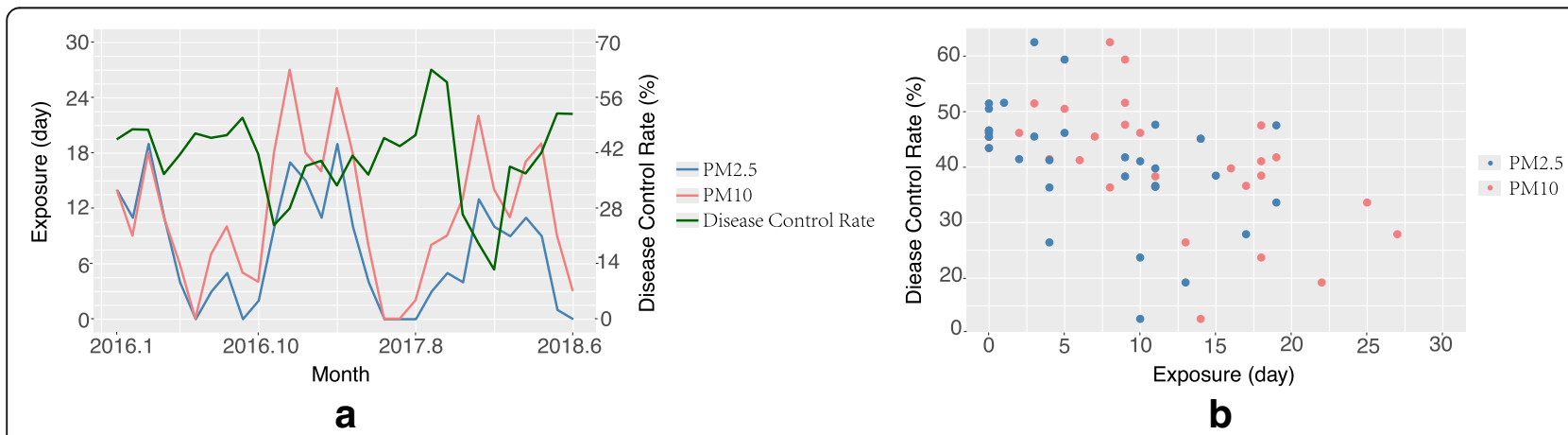

Fig. 5 The association between PM exposure and DCR for childhood asthma. Panel (a):Time series of PM and DCR for childhood asthma during the study period. Panel (b): Distribution of PM exposure and DCR. PM 2.5 (blue) and $\mathrm{PM}_{10}$ (red) were indicated 


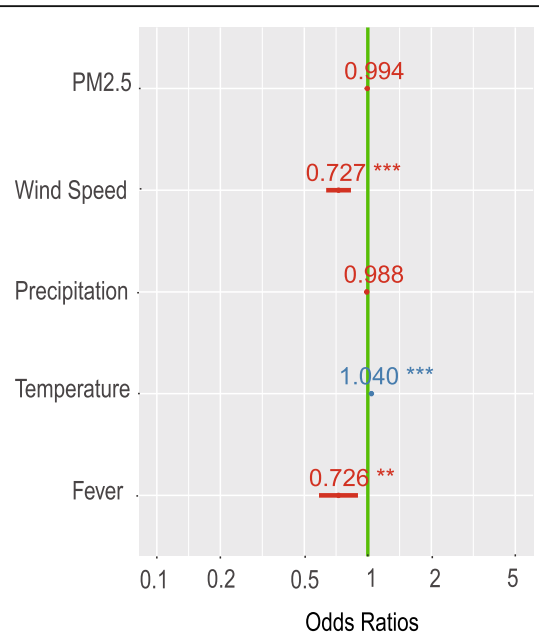

a

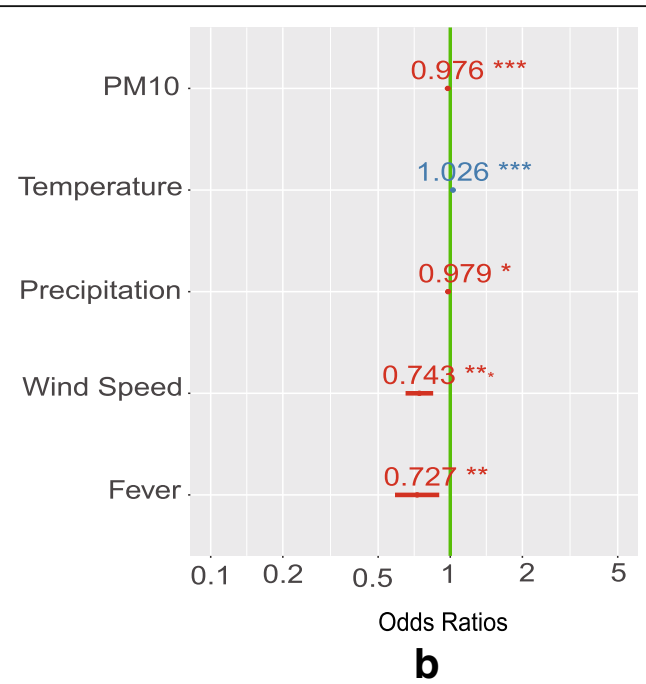

Fig. 6 Odds ratios of each increasing day of exposure to $\mathrm{PM}_{2.5}(\mathbf{a})$ and $\mathrm{PM}_{10}(\mathbf{b})$ on DCR of childhood asthma

macrophages [53]. A number of pathological changes, such as inflammatory cell infiltration, bronchial smooth muscle thickening, and bronchial mucosal injury are observed following the exposure to PM [54]. More recent study shows that certain transcription factors, such as Toll-like receptor and nuclear factor-erythroid 2-ralated factor 2(Nrf2) signaling pathway are involved in the inflammatory responses in the airway of asthmatic mice [55].

The physicochemical property of PM varies substantially due to the source of pollutant as well as climate. It is still not clear what is the exact molecular basis underlying the toxicity of PM. Our results are constrained to the local conditions in Xiamen and may differ from other regions due to the different chemical features of PM. To address the question, systematic chemical description of the PM is needed in future study.

\section{Conclusions}

This study assessed the short-term effects of air pollution and weather conditions on childhood asthma exacerbation and control rate in Xiamen. We confirmed that short-term exposure to PM for one or two weeks increased the risk of exacerbation in asthmatic children and compromises the disease control rate. Our study provides epidemiological data for formulating environmental health policy and clinical prevention of asthma in children. Our findings reaffirmed the necessity of preventive care for asthma susceptible population according to environmental conditions.

Table 4 Odds ratios of asthma control for exposure days toPM 2.5 and $\mathrm{PM}_{10}$

\begin{tabular}{|c|c|c|c|c|c|}
\hline Variable & OR & Standardized OR & \%increase & Standardized 95\%Cl & $P$-value \\
\hline \multicolumn{6}{|l|}{$\mathrm{PM}_{2.5}$} \\
\hline Exposure(day) & 0.994 & 0.959 & -4.10 & {$[0.879,1.046]$} & 0.347 \\
\hline Temperature $\left({ }^{\circ} \mathrm{C}\right)$ & 1.04 & 1.256 & 25.56 & {$[1.155,1.365]$} & $<0.001^{* * *}$ \\
\hline Precipitation(mm) & 0.988 & 0.962 & -3.84 & {$[0.910,1.015]$} & 0.159 \\
\hline Wind Speed(m/s) & 0.727 & 0.883 & -11.72 & {$[0.837,0.931]$} & $<0.001^{* * *}$ \\
\hline Fever & 0.726 & 0.923 & -7.67 & {$[0.876,0.974]$} & $0.003^{* *}$ \\
\hline \multicolumn{6}{|l|}{$\mathrm{PM}_{10}$} \\
\hline Exposure(day) & 0.976 & 0.848 & -15.18 & {$[0.786,0.915]$} & $<0.001^{* * *}$ \\
\hline Temperature $\left({ }^{\circ} \mathrm{C}\right)$ & 1.026 & 1.16 & 16.02 & {$[1.079,1.248]$} & $<0.001^{* * *}$ \\
\hline Precipitation(mm) & 0.979 & 0.934 & -6.62 & {$[0.884,0.987]$} & 0.015 \\
\hline Wind Speed(m/s) & 0.743 & 0.891 & -10.95 & {$[0.846,0.938]$} & $<0.001^{* * *}$ \\
\hline Fever & 0.727 & 0.924 & -7.64 & {$[0.876,0.974]$} & $0.003^{* *}$ \\
\hline
\end{tabular}

${ }^{*} P<0.05,{ }^{* *} P<0.01,{ }^{* * *} P<0.001$ 


\section{Additional files}

Additional file 1: The enrollment criteria of patients in the study. (DOCX $15 \mathrm{~kb}$ )

Additional file 2: Assessment of disease control of asthma for children below and above 6 years old. (PDF $343 \mathrm{~kb}$ )

\section{Abbreviations}

ACQ: Asthma Control Questionnaire; AQI: Air quality index; CCO: CaseCrossover; DCR: Disease control rate; EHR: Electronic health record; ICS: Inhaled corticosteroids; Nrf2: Nuclear factor-erythroid 2-ralated factor 2; OR: Odds ratio; PM: Particulate Matter; RWE: Real-world evidence

\section{Acknowledgments}

We would like to thank Dr. Liyang Zhan for the advices in environmental pollutants.

\section{Availability of data and material}

Datasets used and/or analyzed during the current study are available from the corresponding author on reasonable request.

\section{Funding}

This research was funded by Natural Science Foundation of Fujian Province (No. 2016 J01644). The funding body provided funding for the collection of data and the hardware and software used in this research.

\section{Authors' contributions}

J.W., T.Z., and Q.L. designed the study, analyzed, and interpreted the data, secured the funding for the study, and wrote the paper. Y.Z., D.G., and X.L. helped to collect and analyze data, and critically revise the manuscript. All authors read and approved the manuscript for submission.

\section{Ethics approval and consent to participate}

Ethical clearance was obtained from Ethical Review Board of the First Affiliated Hospital of Xiamen University conforming to the institutional ethical guidance (KY2015-027). All private information, including patient ID, residence and contact information is crypted and hashed. As no private information is revealed in this study, the review board agreed to waive the statement of consent. The usage of the patient records was authorized by the director of the Pediatric Department in the scientific management system.

\section{Consent for publication}

Not Applicable.

\section{Competing interests}

The authors declare that they have no competing interests.

\section{Publisher's Note}

Springer Nature remains neutral with regard to jurisdictional claims in published maps and institutional affiliations.

Received: 30 December 2018 Accepted: 8 May 2019 Published online: 13 June 2019

\section{References}

1. Global Asthma Network. The global asthma report 2018. Auckland, New Zealand.

2. The National Cooperative Group on Childhood Asthma. The third nationwide survy of childhood asthma in urban areas of China. China JPediatr. 2013;51:729-36.

3. Asher MI, Montefort S, Bjorksten B, Lai CK, Strachan DP, Weiland SK, Williams H. Worldwide time trends in the prevalence of symptoms of asthma, allergic rhinoconjunctivitis, and eczema in childhood: ISAAC phases one and three repeat multicountry cross-sectional surveys. Lancet. 2006;368:733-43.

4. Russell G. The childhood asthma epidemic. Thorax. 2006;61:276-8.

5. Ahmadizar F, Vijverberg SJH, Arets HGM, Boer A, Lang JE, Garssen J, Kraneveld A. Maitland-van Der zee AH early-life antibiotic exposure increases the risk of developing allergic symptoms later in life: a meta-analysis. Allergy. 2018;73:971-86.
6. Kelly FJ, Fussell JC. Air pollution and airway disease. Clin Exp Allergy. 2011; 41:1059-71.

7. Asher I, Pearce N. Global burden of asthma among children. Int J Tuberc Lung Dis. 2014;18:1269-78.

8. Li Q, Liu H, Alattar M, Jiang S, Han J, Ma Y, Jiang C. The preferential accumulation of heavy metals in different tissues following frequent respiratory exposure to PM2.5 in rats. Sci Rep. 2015;5.

9. Zhou Z, Liu Y, Duan F, Qin M, Wu F, Sheng W, Yang L, Liu J, He K. Transcriptomic analyses of the biological effects of airborne PM2.5 exposure on human bronchial epithelial cells. PLoS One. 2015;10.

10. Bunyavanich S, Schadt EE. Systems biology of asthma and allergic diseases: a multiscale approach. J Allergy Clin Immunol. 2015;135:31-42.

11. Janssen NAH, Fischer P, Marra M, Ameling C, Cassee FR. Short-term effects of PM2.5, PM10 and PM2.5-10 on daily mortality in the Netherlands. Sci Total Environ. 2013:463:20-6.

12. Kaji DA, Belli AJ, Mccormack MC, Matsui EC, Williams DAL, Paulin L, Putcha $N$, Peng RD, Diette GB, Breysse PN, et al. Indoor pollutant exposure is associated with heightened respiratory symptoms in atopic compared to non-atopic individuals with COPD. Bmc Pulmonary Medicine. 2014;14.

13. Lee B-J, Kim B, Lee K. Air pollution exposure and cardiovascular disease. Toxicological research. 2014;30:71-5.

14. Ying Z, Xu X, Bai Y, Zhong J, Chen M, Liang Y, Zhao J, Liu D, Morishita M, Sun $\mathrm{Q}$, et al. Long-term exposure to concentrated ambient PM2.5 increases mouse blood pressure through abnormal activation of the sympathetic nervous system: a role for hypothalamic inflammation. Environ Health Perspect. 2014;122:79-86.

15. Huang F, Li X, Wang C, Xu Q, Wang W, Luo Y, Tao L, Gao Q, Guo J, Chen S, et al. PM2.5 spatiotemporal variations and the relationship with meteorological factors during 2013-2014 in Beijing, China. PLoS One. 2015;10.

16. Wu J, Xie W, Li W, Li J. Effects of urban landscape pattern on PM2.5 pollution-a Beijing case study. PLoS One. 2015;10.

17. Reid CE, Jerrett M, Tager IB, Petersen ML, Mann JK, Balmes JR. Differential respiratory health effects from the 2008 northern California wildfires: a spatiotemporal approach. Environ Res. 2016;150:227-35.

18. Ali Abdalla A, Mohammed O, Ghmaird A, Albalawi S, Jad N, Mirghani H, Mursal A, Amirthalingam P. Association of triggering factors with asthma exacerbations among the pediatric population in Tabuk. Kingdom of Saudi Arabia. 2016;5.

19. DePriest K, Butz A. Neighborhood-level factors related to asthma in children living in urban areas: an integrative literature review. J Sch Nurs. 2017:33(1):8-17.

20. Pablo-Romero MP, Roman R, Gonzalez Limon JM, Praena-Crespo M. Effects of fine particles on children's hospital admissions for respiratory health in Seville, Spain. J Air Waste Manage Assoc. 2015;65:436-44.

21. Jedrychowski WA, Perera FP, Spengler JD, Mroz E, Stigter L, Flak E, Majewska R, Klimaszewska-Rembiasz M, Jacek R. Intrauterine exposure to fine particulate matter as a risk factor for increased susceptibility to acute broncho-pulmonary infections in early childhood. Int J Hyg Environ Health. 2013;216:395-401

22. Iskandar A, Andersen ZJ, Bonnelykke K, Ellermann T, Andersen KK, Bisgaard $\mathrm{H}$. Coarse and fine particles but not ultrafine particles in urban air trigger hospital admission for asthma in children. Thorax. 2012;67:252-7.

23. Samoli E, Nastos PT, Paliatsos AG, Katsouyanni K, Priftis KN. Acute effects of air pollution on pediatric asthma exacerbation: evidence of association and effect modification. Environ Res. 2011;111:418-24.

24. Son J, Lee J, Park Y, Bell M. Short-term effects of air pollution on hospital admissions in Korea. Epidemiology. 2013;24:545-54.

25. Kumar SS, Muthuselvam P, Pugalenthi V, Subramanian N, Ramkumar KM, Suresh T, Suzuki T, Rajaguru P. Toxicoproteomic analysis of human lung epithelial cells exposed to steel industry ambient particulate matter (PM) reveals possible mechanism of PM related carcinogenesis. Environ Pollut. 2018:239:483-92.

26. Pfeffer PE, Ho TR, Mann EH, Kelly FJ, Sehlstedt M, Pourazar J, Dove RE, Sandstrom T, Mudway IS, Hawrylowicz CM. Urban particulate matter stimulation of human dendritic cells enhances priming of naive CD8 T lymphocytes. Immunology. 2018;153:502-12.

27. Mallol J, Crane J, Von Mutius E, Odhiambo J, Keil U, Stewart A. The international study of asthma and allergies in childhood (ISAAC) phase three: a global synthesis. Allergol Immunopathol. 2013;41:73-85.

28. Shannon MW, Best D, Binns HJ, Johnson CL, Kim JJ, Mazur LJ, Reynolds DW, Roberts JR, Weil WB, Balk SJ, et al. Ambient air pollution: health hazards to children. Pediatrics. 2004;114:1699-707. 
29. Bateson TF, Schwartz J. Children's response to air pollutants. Journal of Toxicology and Environmental Health-Part a-Current Issues. 2008;71:238-43.

30. The Subspecialty Group of Respirology. The Society of Pediatrics, Chinese Medical Association guidelines for the diagnosis and prevention of asthma in children (2016). Chin. J Pediatr. 2016. https://doi.org/10.3760/ema.j.issn. 0578-1310.2016.03.003.

31. Park HJ, Byun MK, Kwon J-W, Kim WK, Nahm D-H, Lee M-G, Lee S-P, Lee SY, Lee J-H, Jeong YY, et al. Video education versus face-to-face education on inhaler technique for patients with well-controlled or partly-controlled asthma: a phase IV, open-label, non-inferiority, multicenter, randomized, controlled trial. PLoS One. 2018;13(8).

32. Adachi M, Hozawa S, Nishikawa M, Yoshida A, Jinnai T, Tamura G. Asthma control and quality of life in a real-life setting: a cross-sectional study of adult asthma patients in Japan (ACQUIRE-2). The Journal of asthma : official journal of the Association for the Care of Asthma. 2018:1-10.

33. Ministry of Environmental Protection of P. R. C. Technical requirements for environmental air quality index (AQI) (for Trial Implementation). Journal of China Environmental Management Cadre College. 2012;22:44.

34. Kloog I, Coull BA, Zanobetti A, Koutrakis P. Schwartz JD acute and chronic effects of particles on hospital admissions in new-England. PLoS One. 2012;7(8).

35. Norris G, Youngpong SN, Koenig JQ, Larson TV, Sheppard L, Stout JW. An association between fine particles and asthma emergency department visits for children in Seattle. Environ Health Perspect. 1999;107:489-93.

36. Chen K, Glonek G, Hansen A, Williams S, Tuke J, Salter A, Bi P. The effects of air pollution on asthma hospital admissions in Adelaide, South Australia, 2003-2013: time-series and case-crossover analyses. Clin Exp Allergy. 2016; 46:1416-30.

37. Kuo CY, Pan RH, Chan CK, Wu CY, Phan DV, Chan CL. Application of a timestratified case-crossover design to explore the effects of air pollution and season on childhood asthma hospitalization in cities of differing urban patterns: big data analytics of government open data. Int J Environ Res Public Health. 2018;15(15).

38. Li G, Huang J, Xu G, Pan X, Qian X, Xu J, Zhao Y, Zhang T, Liu Q, Guo X, et al. The short term burden of ambient fine particulate matter on chronic obstructive pulmonary disease in Ningbo, China. Environ Health. 2017;16.

39. Chang J-H, Hsu S-C, Bai K-J, Huang S-K, Hsu C-W. Association of time-serial changes in ambient particulate matters (PMs) with respiratory emergency cases in Taipei's Wenshan District. PLoS One. 2017;12(7).

40. Kim H, Kim H, Park YH, Lee JT. Assessment of temporal variation for the risk of particulate matters on asthma hospitalization. Environ Res. 2017;156:542-50.

41. Martenies SE, Batterman SA. Effectiveness of using enhanced filters in schools and homes to reduce indoor exposures to PM2.5 from outdoor sources and subsequent health benefits for children with asthma. Environmental Science \& Technology. 2018;52(18):10767-76.

42. Mirabelli MC, Golan R, Greenwald R, Raysoni AU, Holguin F, Kewada P, Winquist A, Flanders WD, Sarnat JA. Modification of traffic-related respiratory response by asthma control in a population of Car commuters. Epidemiology. 2015;26:546-55.

43. Zora JE, Sarnat SE, Raysoni AU, Johnson BA, Li W-W, Greenwald R, Holguin F, Stock TH, Sarnat JA. Associations between urban air pollution and pediatric asthma control in El Paso, Texas. Sci Total Environ. 2013;448:56-65.

44. Woods KE, Apsley A, Semple S, Turner SW. Domestic airborne fine particulate matter exposure and asthma control among children receiving inhaled steroid treatment. Indoor and Built Environment. 2014;23:497-503.

45. Van Weel C, Bateman ED, Bousquet J, Reid J, Grouse L, Schermer T, Valovirta E, Zhong N. Asthma management pocket reference 2008. Allergy. 2008; 63(8):997-1004.

46. Bateman ED, Reddel HK, Eriksson G, Peterson S, Ostlund O, Sears MR, Jenkins C, Humbert M, Buhl R, Harrison TW, et al. Overall asthma control: the relationship between current control and future risk. J Allergy Clin Immunol. 2010;125(3):600-8.

47. De Grove KC, Provoost S, Brusselle GG, Joos GF, Maes T. Insights in particulate matter-induced allergic airway inflammation: focus on the epithelium. ClinExp Allergy. 2018;48(7):773-86.

48. De HC, Hassing I, Bol M, Bleumink R, Pieters R. Ultrafine but not fine particulate matter causes airway inflammation and allergic airway sensitization to co-administered antigen in mice. Clin Exp Allergy. 2010; 36(11):1469-79.

49. Haar CD, Hassing I, Bol M, Bleumink R, Pieters R. Ultrafine carbon black particles cause early airway inflammation and have adjuvant activity in a mouse allergic airway disease model. Toxicological Sciences An Official Journal of the Society of Toxicology. 2005;87(2):409.

50. Mcgee MA, Kamal AS, Mcgee JK, Wood CE, Dye JA, Krantz QT, Landis MS, Gilmour MI, Gavett SH. Differential effects of particulate matter upwind and downwind of an urban freeway in an allergic mouse model. Environmental Science \& Technology. 2015;49(6):3930-9.

51. Xingliang Z, Wenqing Z, Qingqi M, Qianwen L, Chao F, Xiulan H, Chengyan $L$, Yuge $H$, Jianxin T. Ambient PM2.5 exposure exacerbates severity of allergic asthma in previously sensitized mice. Journal of Asthma Official Journal of the Association for the Care of Asthma. 2015;52(8):785-94.

52. Wang Y-H, Lin Z-Y, Yang L-W, He H-J, Chen T, Xu W-Y, Li C-Y, Zhou X, Li D$M$, Song $Z-Q$, et al. PM2.5 exacerbate allergic asthma involved in autophagy signaling pathway in mice. Int J Clin Exp Pathol. 2016;9(12):12247-61.

53. Becker S, Mundandhara S, Devlin RB, Madden M. Regulation of cytokine production in human alveolar macrophages and airway epithelial cells in response to ambient air pollution particles: further mechanistic studies. Toxicol Appl Pharmacol. 2005;207(2 Suppl):269-75.

54. Liu MH, Fan X, Wang N, Zhang Y, Yu J. Exacerbating effects of PM2.5 in OVA-sensitized and challenged mice and the expression of TRPA1 and TRPV1 protein in lung. Journal of Asthma Official Journal of the Association for the Care of Asthma. 2017;54(8):1-11

55. Deng X, Rui W, Zhang F, Ding W. PM2.5 induces Nrf2-mediated defense mechanisms against oxidative stress; by activating PIK3/AKT signaling pathway in human lung alveolar; epithelial A549 cells. Cell Biology \& Toxicology. 2013;29(3):143-57.

\section{Ready to submit your research? Choose BMC and benefit from:}

- fast, convenient online submission

- thorough peer review by experienced researchers in your field

- rapid publication on acceptance

- support for research data, including large and complex data types

- gold Open Access which fosters wider collaboration and increased citations

- maximum visibility for your research: over $100 \mathrm{M}$ website views per year

At $\mathrm{BMC}$, research is always in progress.

Learn more biomedcentral.com/submissions 